OPEN ACCESS

Edited by:

Melissa Ann Kalarchian, Duquesne University, United States

Reviewed by: Bárbara Oliván Blázquez, University of Zaragoza, Spain Karin Meissner, Hochschule Coburg, Germany

${ }^{*}$ Correspondence: Christina Holzapfel Christina.Holzapfel@tum.de

Specialty section: This article was submitted to Psychosomatic Medicine, a section of the journal

Frontiers in Psychiatry

Received: 16 January 2020 Accepted: 12 June 2020

Published: 03 July 2020

Citation:

Bayer S, Drabsch T, Schauberger G, Hauner H and Holzapfel C (2020)

Responsibility of Individuals and Stakeholders for Obesity and a Healthy Diet: Results From a German Survey.

Front. Psychiatry 11:616. doi: 10.3389/fpsyt.2020.00616

\section{Responsibility of Individuals and Stakeholders for Obesity and a Healthy Diet: Results From a German Survey}

\author{
Sandra Bayer ${ }^{1}$, Theresa Drabsch ${ }^{1}$, Gunther Schauberger ${ }^{2}$, Hans Hauner ${ }^{1,3}$ \\ and Christina Holzapfel ${ }^{1 \text { * }}$ \\ ${ }^{1}$ School of Medicine, Institute for Nutritional Medicine, Technical University of Munich, Munich, Germany, ${ }^{2}$ Chair of \\ Epidemiology, Department of Sport and Health Sciences, Technical University of Munich, Munich, Germany, ${ }^{3}$ ZIEL - Institute \\ for Food \& Health, Technical University of Munich, Freising, Germany
}

Introduction: Overweight and obesity are thought to be mainly caused by an energy-rich diet and a sedentary lifestyle. The opinions of those with and without obesity about an individual's and stakeholder's responsibility for overweight and obesity as well as a healthy diet is rather unclear. Therefore, a survey was conducted to assess the thoughts of persons with and without obesity about the responsibilities for a high body weight and healthy diet.

Methods: This telephone-based survey was conducted in Germany. Landline and mobile phone users older than 17 years were quota sampled to represent the German population $(n=1,003)$. Additionally, 354 adults with a body mass index $(B M I) \geq 30 \mathrm{~kg} / \mathrm{m}^{2}$ were included in the survey population. Questions on weight management, eating and drinking and anthropometry were asked. Furthermore, the opinions of participants on the responsibility of individuals and stakeholders for obesity and a healthy diet were collected. Data was statistically weighted by age, gender, education, domicile, and BMI.

Results: Data of 1,357 persons (51.1\% female, age: $50.5 \pm 18.5$ years, $15.9 \%$ with $\mathrm{BMI} \geq$ $30 \mathrm{~kg} / \mathrm{m}^{2}$ ) were analyzed. Participants responded that the general causes of a high body weight were low physical activity (82.7\%) and excessive caloric intake (80.5\%) followed by a lack of will power $(72.1 \%)$. Almost $90 \%$ of the survey population reported that each individual is responsible for his/her own healthy diet. More than $85 \%$ of the survey population agreed that a healthy diet in kindergarten and nutrition education at schools should be the preferred approaches when politics take care of a person's healthy diet. Sub-analyses revealed that BMI, sex, age, and education are potential confounders.

Conclusion: This German survey showed that the majority of participants indicated that the responsibility for a healthy diet lies with the individual and high body weight is caused by self-controlled attitudes. These results suggest that the survey population underestimates societal and environmental factors that contribute to the development of obesity, which could lead to attitudes that facilitate weight-related stigmatization. 


\section{Furthermore, survey participants indicated that they would support policy-driven} measures that promote a healthy diet.

Keywords: healthy diet, responsibility, political approaches, obesity, survey, Germany

\section{INTRODUCTION}

The increasing prevalence of obesity has become a global burden (1-3). While in 1980 about 851 million people were overweight or obese, the number ( 2.1 billion) is more than double in 2013 (2). In Germany, the prevalence of overweight $(67.1 \%$ men, $53.0 \%$ women) has been nearly stable over the last 20 years. However, the number of adults (4) as well as children and adolescents (2) with obesity continued to increase during this time. Obesity is a major modifiable determinant in the development of many non-communicable diseases (NCDs) (5, 6). In $2016,71 \%$ of global deaths were estimated to be caused by NCDs (7). Therefore, more efforts to prevent obesity and to facilitate a healthy lifestyle are needed to significantly reduce the number of global deaths due to NCDs (6).

Obesity is mostly driven by an excess of caloric intake and a sedentary lifestyle (5). Prevention strategies have mainly focused on the individual level (8). However, the development of obesity is complex and is also caused by the current obesogenic environment $(5,9)$. A literature review concluded that there is an interaction between the obesogenic environment and the individual lifestyle (10). The World Health Organization (WHO) stated that the burden of obesity can only be reduced when individuals have access to an environment that facilitates a healthy lifestyle (5). Hence, the WHO initiated a Global Action Plan for the Prevention and Control of Non-communicable Diseases to decrease the prevalence of NCDs by 25\% worldwide until 2025 (11). This should be achieved by implementing prevention strategies on both the individual and the population level.

Studies have shown that the stigmatization of people with obesity is frequent and a major concern (12-14). One reason for this is that the public generally does not view obesity as a medical condition, whereas experts consider obesity to be a chronic disease (15). The media and the public often communicate that obesity is the result of a loss of self-control, leading to high energy intake and lack of physical activity. This misconception promotes the stigmatization of people with overweight and obesity and impedes their adequate care. Besides, a policymaker survey from the European Association for the Study of Obesity (EASO) explored the extent to which policymakers recognize their responsibility in reducing the prevalence of obesity (16). Policymakers answered that individuals, families and the food industry are most responsible for tackling obesity in the future (16). Addressing stigmatization and discrimination as well as the responsibility of policymakers to change the obesogenic environment are therefore rarely on the agenda. Increased attention on the misconceptions regarding the origin of obesity is warranted. Stakeholders and policymakers should be encouraged to develop a plan that facilitates adopting a healthy lifestyle in all stages of life by promoting preventive and therapeutic strategies that are free and accessible to all. To achieve these goals, more data from the general population are needed.

The opinion of those with and without obesity regarding the reasons for developing overweight and obesity is rather unclear. Likewise, a focus group study explored beliefs from the general population regarding the individual and stakeholder's responsibility to promote a healthy diet and to prevent high body weight (17). Therefore, the aim of this representative, as well as target group-specific survey was to collect data on the beliefs and perceptions from a representative sample of the German population about the individual versus societal responsibilities regarding obesity development and a healthy diet.

\section{METHODS}

\section{Sample Characteristics}

Between January and March 2019, a nationwide telephone-based survey was conducted in Germany by USUMA GmbH, a social research and market analysis company. A scientific Random Digit Dialing (RDD) method (ADM-Sampling System, Dual Frame) was used to randomly sample landline and mobile phone users who were at least 18 years old. The used RDD sampling frame followed a further developed version of the Gabler-Häder procedure, which allowed potential participants who were not listed in official registers to be contacted. About $40 \%$ of the initial sample were mobile numbers, as $15 \%$ of the German population do not have access to landline connections. For the random selection of a participant within one household, the Kish selection grid was used (USUMA Markt- und Sozialforschung, Berlin, Germany).

For the representative sample, 2,361 subjects were contacted. A response rate of $42.5 \%(\mathrm{~N}=1,003)$ was achieved. To compare the results between persons with a $\mathrm{BMI}<30.0 \mathrm{~kg} / \mathrm{m}^{2}$ and persons with a $\mathrm{BMI} \geq 30.0 \mathrm{~kg} / \mathrm{m}^{2}$, target group-specific interviews for persons with obesity $(\mathrm{N}=354)$ were added. This sampling was complementary to the representative sample. In total, data from 1,357 subjects were collected, of whom 505 participants had a BMI $\geq 30.0 \mathrm{~kg} / \mathrm{m}^{2}$. Each interview took about 25 minutes and was conducted by trained staff. Due to the performance of the survey by a professional provider, this survey was not approved by the local ethical review committee. Participants provided their oral informed consent before participation, under the premise that participation in this survey was voluntary and analyses are conducted anonymously. Oral consent is common in representative survey research in Germany to avoid bias through non-response. 


\section{Development of the Questionnaire}

The survey team developed a standardized survey-specific questionnaire based on the ideas collected in two focus groups $\left(\mathrm{BMI}<30.0 \mathrm{~kg} / \mathrm{m}^{2}, \mathrm{BMI} \geq 30.0 \mathrm{~kg} / \mathrm{m}^{2}\right)$. Before finalizing the questionnaire, it was pretested in paper form and evaluated in terms of understanding and length by 30 computer-assistant telephone-based interviews (CATI) by trained staff.

At the beginning of the interview, each person was informed about the research project, voluntary participation and data protection. Data about sociodemographic variables (age, gender, marital status, education, occupation, migration background) were collected by 10 questions. BMI was calculated according to the WHO criteria (18), using self-reported anthropometric data (height, weight) (4 questions). As BMI was a major parameter for the subanalyses, a computer-based method was implemented, which allowed to calculate the BMI without naming the actual weight. First, body height, which was mandatory for participation, was asked. By reluctance to name the body height, the person was excluded and the interview has been stopped. After mentioning body height, the participant was asked for his body weight to calculate the BMI with the equation BMI = weight in kilogram/ (height in meters) ${ }^{2}$. In case of reluctance to report body weight, the interviewer asked for pre-calculated weight ranges that allowed to calculate the participant's BMI according to the WHO criteria (underweight/normal weight: BMI $<25.0 \mathrm{~kg} / \mathrm{m}^{2}$, overweight: BMI $25.0-29.9 \mathrm{~kg} / \mathrm{m}^{2}$, obesity: BMI $\geq 30.0 \mathrm{~kg} / \mathrm{m}^{2}$ ). This method was applied by five participants who did not report their body weight. In total, 42 questions were asked. The main part of the questionnaire was divided into four topics - weight management (4 questions), nutritional questions (2 questions: dietary habits, 1 question: responsibility, 1 question: political approaches), state of knowledge of personalized genotype-based dietary recommendations (6 questions) and opinions and expectations of personalized genotype-based dietary recommendations (14 questions).

Screening questions were used to tailor the questionnaire to individual participants. For example, if participants responded to certain questions with "no" or "I do not know", some related questions were skipped. The questionnaire consisted of openended, semi-closed and closed questions with single and multichoice answer options. Several questions had responses based on a five-point Likert scale (e.g. $1=$ not important to $5=$ very important). Participants were also given the choice of responding with "no answer" to decrease response bias. The present analysis was focused on the responsibility of individuals and stakeholders for a high body weight and a healthy diet.

\section{Data Analysis}

Before analyzing, data were statistically weighted by age, gender, education and domicile according to the population demographics by iterative proportional fitting (19). Furthermore, the percental distribution of persons with BMI $<30.0 \mathrm{~kg} / \mathrm{m}^{2}$ and $\geq 30.0 \mathrm{~kg} / \mathrm{m}^{2}$ of the total sample $(\mathrm{N}=1,357)$ was proportioned to represent the percental distribution of persons with $\mathrm{BMI}<30.0 \mathrm{~kg} / \mathrm{m}^{2}$ and $\geq 30.0$ $\mathrm{kg} / \mathrm{m}^{2}$ of the initial sample $(\mathrm{N}=1,003)$. Therefore, 852 persons with a $\mathrm{BMI}<30.0 \mathrm{~kg} / \mathrm{m}^{2}$ represent $1,141(84.1 \%)$ persons and 505 persons with a $\mathrm{BMI} \geq 30.0 \mathrm{~kg} / \mathrm{m}^{2}$ represent 216 (15.9\%) persons within the total sample population (1,357 interviews). Due to this, the percental distribution of the BMI categories was according to the population demographics and no further iterative proportional fitting was done. The different variables within each question were randomly chosen for each survey participant to avoid order bias. Because of screening questions, the number of questions per participant was varying. Missing values including answers with "no answer" or "I do not know" were eliminated listwise in the analysis. For the present work, 16 questions were used for the statistical analysis. The results of the other questions are published elsewhere (Bayer S et al., submitted). The statistical software program SPSS (SPSS version 25.0, SPSS Inc., Chicago, IL, USA) was used for the descriptive statistics (frequencies and percentages). Analyses were performed for the total sample as well as for subgroups such as BMI $\left(B M I<30.0 \mathrm{~kg} / \mathrm{m}^{2}, \mathrm{BMI} \geq 30.0 \mathrm{~kg} / \mathrm{m}^{2}\right)$, gender, age, and education, because subgroup differences were assumed. Furthermore, in the statistical software R (20) weighted Chi-squared independence tests were performed to compare the respective subgroups. In cases, where the proportions of three answer categories were compared, the test refers to the comparison of categories $(1,2)$ vs. 3 . For each test, the corresponding p-values for the null hypothesis of equal proportions among all subgroups was reported. Data are shown as numbers and percentages of the total sample.

\section{RESULTS}

\section{Characteristics of the Participants}

In Table 1, the characteristics of the survey population are summarized. In total, 1,357 people participated in the survey, of whom $51.1 \%(694 / 1,357)$ were female, $53.0 \%(718 / 1,353)$ were married and $37.7 \%(482 / 1,279)$ reported having a higher education entrance qualification. The mean age was $50.5 \pm 18.5$ years. Half of the survey population was employed $(726 / 1,356)$ and $18.5 \%(243 / 1,311)$ had a migration background (Table 1). Respondents reported a calorie-reduced diet (55.3\%, 401/725), a low-carb diet $(49.4 \%, 358 / 725)$ and a low-fat diet (48.1\%, 349/725) as weight loss strategies most often tried (Table 2). About $77 \%$ $(77.3 \%, 1,048 / 1,355)$ of the survey population reported that what they eat and drink is important to them (Table 3).

\section{Responsibilities for Obesity and a Healthy Diet}

When asking about the general cause of a high body weight, the survey population mostly named low physical activity $(82.7 \%$, $1,120 / 1,354)$ and excessive caloric intake $(80.5 \%, 1,079 / 1,341)$, followed by lack of will power $(72.1 \%, 959 / 1,330)$ (Table 4). No statistically significant differences between the BMI groups could be found concerning the most stated variables $(p>0.05)$. The most stated causes of a high body weight significantly differed between education levels ( $\mathrm{p} \leq 0.01$ ). Additionally, a significantly different percental distribution could be seen between the age 
TABLE 1 | Characteristics of the survey population.

\begin{tabular}{|c|c|c|}
\hline \multirow[t]{2}{*}{ Variable } & \multicolumn{2}{|c|}{ Number } \\
\hline & $\mathrm{n} / \mathrm{N}^{\#}$ & $\%$ \\
\hline \multicolumn{3}{|l|}{ Gender } \\
\hline Female & $694 / 1,357$ & 51.1 \\
\hline Male & $663 / 1,357$ & 48.9 \\
\hline \multicolumn{3}{|l|}{ Age (years) } \\
\hline 18-35 & $345 / 1,357$ & 25.5 \\
\hline $36-65$ & $690 / 1,357$ & 50.8 \\
\hline$>65$ & $322 / 1,357$ & 23.7 \\
\hline \multicolumn{3}{|l|}{$B M I\left(k g / m^{2}\right)$} \\
\hline$<18.5$ & $19 / 1,357$ & 1.4 \\
\hline 18.5-24.9 & $662 / 1,357$ & 48.8 \\
\hline 25-29.9 & $459 / 1,357$ & 33.8 \\
\hline$\geq 30$ & $216 / 1,357$ & 15.9 \\
\hline \multicolumn{3}{|l|}{ Marital status } \\
\hline Single & $415 / 1,353$ & 30.7 \\
\hline Married & $718 / 1,353$ & 53.0 \\
\hline Divorced/widowed & $220 / 1,353$ & 16.3 \\
\hline \multicolumn{3}{|l|}{ Education (years) $^{1}$} \\
\hline Student & $3 / 1,279$ & 0.2 \\
\hline $8 / 9$ & $360 / 1,279$ & 28.1 \\
\hline 10 & $424 / 1,279$ & 33.2 \\
\hline $12 / 13$ & $482 / 1,279$ & 37.7 \\
\hline No education & $10 / 1,279$ & 0.8 \\
\hline Occupation & 726/1,356 & 53.6 \\
\hline Immigrant background & 243/1,311 & 18.5 \\
\hline
\end{tabular}

${ }^{1}$ What is your highest level of education? Possible answers: still studying, certificate of secondary education (8/9 years), a general certificate of secondary education (10 years), higher education entrance certification (12/13 years), no student/education, no answer. "Persons with answers "no answer" are not included in statistical analysis. The number of those answers can be calculated by the difference between the total population $(N=1,357)$ and the number of answers given for each variable.

BMI, body mass index; data is statistically weighted by age, gender, education, domicile and BMI.

groups for the variables excessive caloric intake and lack of will power $(\mathrm{p} \leq 0.01)$ (Table 4).

Almost $90 \%(89.1 \%, 1,197 / 1,343)$ of the survey population stated that the individual is responsible for a healthy diet, followed by the family $(74.7 \%, 1,006 / 1,347)$ (Table 5). Both variables were named more often by women than men ( $\mathrm{p}$ $0.001)$. Futhermore, participants with $\mathrm{BMI} \geq 30.0 \mathrm{~kg} / \mathrm{m}^{2}$ responded more often that the individual is responsible for a person's healthy diet than participants with BMI $<30.0 \mathrm{~kg} / \mathrm{m}^{2}$ ( $\mathrm{p} \leq 0.05$ ). Additionally, statistically significant differences could be seen between the different education groups concerning the responsibility of the family for a person's healthy diet $(\mathrm{p} \leq 0.001)$ (Table 5).

Most participants responded to prefer most promoting regional and seasonal foods $(82.8 \%, 1,099 / 1,327)$, nutrition education in school $(86.1 \%, 1,148 / 1,333)$ and implementation of a healthy diet in the kindergarten $(88.4 \%, 1,185 / 1,340)$ when the policy should take care of a person's healthy diet (Table 6). The taxation of specific foods was observed to be the least preferred political approach $(41.6 \%, 550 / 1,323)$ (Table 6). No statistically significant differences between BMI groups could be observed except for one political approach. Participants with $\mathrm{BMI}<30.0 \mathrm{~kg} / \mathrm{m}^{2}$ answered more often to prefer political approaches supporting a healthy diet by promoting regional and seasonal foods than participants with $\mathrm{BMI} \geq 30.0 \mathrm{~kg} / \mathrm{m}^{2}$

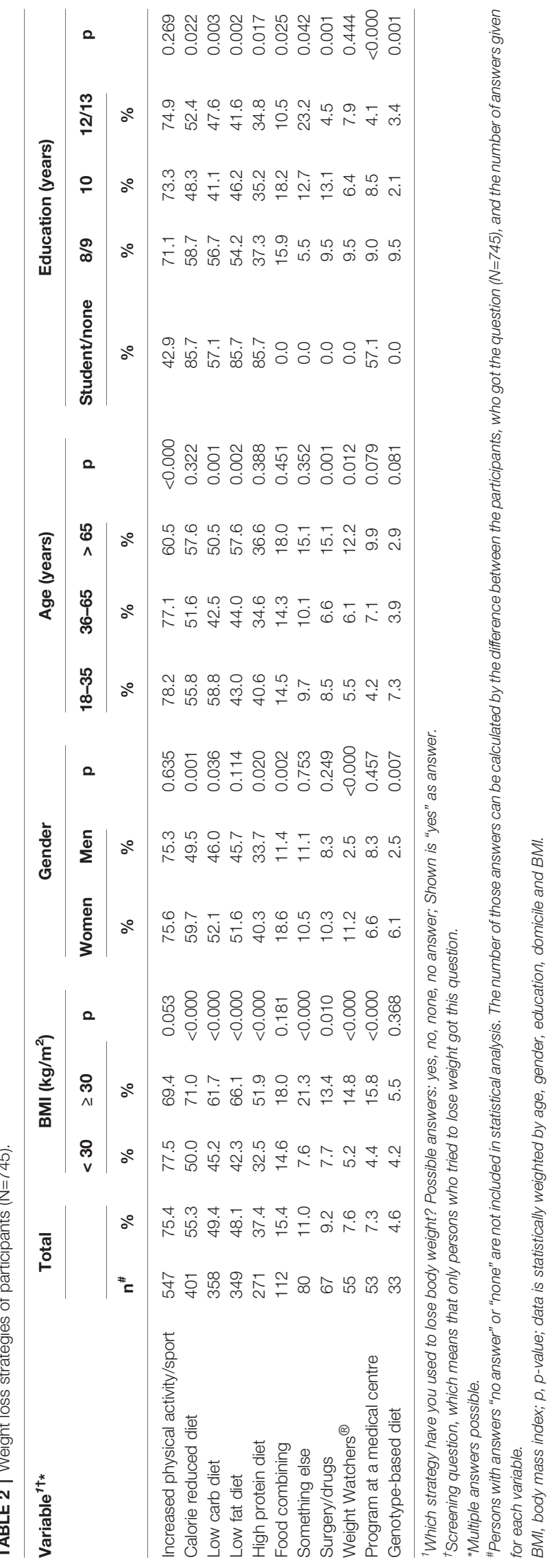


TABLE 3 | Importance of eating and drinking.

\begin{tabular}{|c|c|c|c|c|c|c|c|c|c|c|c|c|c|c|c|c|c|c|}
\hline \multirow[t]{3}{*}{ Variable } & \multirow[t]{3}{*}{ Answer ${ }^{\dagger}$} & \multicolumn{2}{|l|}{ Total } & \multicolumn{3}{|c|}{ BMI $\left(\mathrm{kg} / \mathrm{m}^{2}\right)$} & \multicolumn{3}{|c|}{ Gender } & \multicolumn{4}{|c|}{ Age (years) } & \multicolumn{5}{|c|}{ Education (years) } \\
\hline & & & & $<30$ & $\geq 30$ & $p$ & Women & Men & $p$ & $18-35$ & $36-65$ & $>65$ & $p$ & Student/none & $8 / 9$ & 10 & $12 / 13$ & $p$ \\
\hline & & $\mathrm{n} / \mathrm{N}^{\#}$ & $\%$ & $\%$ & $\%$ & & $\%$ & $\%$ & & $\%$ & $\%$ & $\%$ & & $\%$ & $\%$ & $\%$ & $\%$ & \\
\hline \multirow{3}{*}{$\begin{array}{l}\text { Importance of what you eat and } \\
\text { drink }^{1}\end{array}$} & 1 & $52 / 1,355$ & 3.8 & 3.3 & 7.0 & & 4.6 & 3.0 & & 3.2 & 3.8 & 4.7 & & 0.0 & 4.2 & 4.5 & 3.1 & \\
\hline & 2 & $255 / 1,355$ & 18.8 & 16.9 & 28.8 & & 15.4 & 22.5 & & 24.6 & 15.1 & 15.7 & & 17.6 & 22.6 & 18.8 & 16.3 & \\
\hline & 3 & $1,048 / 1,355$ & 77.3 & 79.8 & 64.2 & $<0.000$ & 80.0 & 74.5 & 0.014 & 72.2 & 81.2 & 74.7 & 0.001 & 76.9 & 73.3 & 76.7 & 80.6 & 0.086 \\
\hline \multicolumn{19}{|l|}{$\begin{array}{l}\text { Importance of facts for eating } \\
\text { and drinking }{ }^{2}\end{array}$} \\
\hline Food rich in fibre & 1 & $219 / 1,354$ & 16.2 & 15.1 & 21.5 & & 11.7 & 20.9 & & 26.2 & 13.8 & 10.6 & & 38.5 & 17.8 & 14.9 & 16.1 & \\
\hline \multirow{2}{*}{ (e.g. whole grain products) } & 2 & $330 / 1,354$ & 24.4 & 23.8 & 27.6 & & 24.7 & 24.1 & & 28.2 & 24.5 & 19.9 & & 15.4 & 24.0 & 23.6 & 25.7 & \\
\hline & 3 & $805 / 1,354$ & 59.5 & 61.1 & 50.9 & 0.005 & 63.6 & 55.1 & 0.001 & 45.6 & 61.7 & 69.5 & $<0.000$ & 38.5 & 58.2 & 61.5 & 58.2 & 0.358 \\
\hline \multirow{3}{*}{$\begin{array}{l}\text { Self-prepared and fresh meals } \\
\text { (e.g. no convenience products) }\end{array}$} & 1 & $129 / 1,350$ & 9.6 & 9.0 & 13.2 & & 7.1 & 12.2 & & 10.4 & 9.2 & 9.7 & & 53.8 & 9.2 & 9.5 & 9.1 & \\
\hline & 2 & $193 / 1,350$ & 14.3 & 14.1 & 15.6 & & 8.5 & 20.4 & & 21.7 & 12.8 & 9.1 & & 0.0 & 12.8 & 14.7 & 14.9 & \\
\hline & 3 & $1,028 / 1,350$ & 76.1 & 77.0 & 72.1 & 0.074 & 84.4 & 67.4 & $<0.000$ & 67.8 & 78.1 & 81.1 & $<0.000$ & 46.2 & 77.9 & 75.8 & 75.9 & 0.115 \\
\hline \multirow[t]{3}{*}{ Adequate fluids } & 1 & $92 / 1,356$ & 6.8 & 6.4 & 9.2 & & 5.6 & 8.0 & & 8.4 & 6.7 & 5.3 & & 23.1 & 7.5 & 6.4 & 6.7 & \\
\hline & 2 & $152 / 1,356$ & 11.2 & 11.0 & 12.4 & & 11.3 & 11.2 & & 16.8 & 8.6 & 10.9 & & 0.0 & 13.3 & 11.1 & 11.2 & \\
\hline & 3 & $1,112 / 1,356$ & 82.0 & 82.6 & 78.3 & 0.144 & 83.1 & 80.8 & 0.283 & 74.9 & 84.6 & 83.8 & $<0.000$ & 76.9 & 79.2 & 82.5 & 82.1 & 0.567 \\
\hline \multirow[t]{3}{*}{ Small portions } & 1 & 306/1,344 & 22.8 & 22.8 & 22.8 & & 15.8 & 29.7 & & 41.4 & 17.5 & 13.5 & & 69.2 & 18.1 & 23.2 & 26.4 & \\
\hline & 2 & $478 / 1,344$ & 35.6 & 35.6 & 35.3 & & 35.5 & 35.8 & & 35.9 & 35.9 & 33.7 & & 7.7 & 34.8 & 36.0 & 38.7 & \\
\hline & 3 & $560 / 1,344$ & 41.7 & 41.6 & 41.9 & 0.960 & 48.7 & 34.5 & $<0.000$ & 22.6 & 46.2 & 52.9 & $<0.000$ & 23.1 & 47.1 & 40.8 & 34.9 & 0.003 \\
\hline \multirow[t]{3}{*}{ Balanced and healthy diet } & 1 & $90 / 1,357$ & 6.6 & 5.3 & 13.4 & & 4.2 & 9.2 & & 10.1 & 5.8 & 4.0 & & 30.8 & 7.5 & 6.6 & 6.0 & \\
\hline & 2 & $185 / 1,357$ & 13.6 & 11.6 & 24.4 & & 10.2 & 17.2 & & 18.3 & 12.6 & 11.2 & & 46.2 & 13.9 & 14.9 & 11.0 & \\
\hline & 3 & $1,082 / 1,357$ & 79.7 & 83.1 & 62.2 & $<0.000$ & 85.6 & 73.6 & $<0.000$ & 71.6 & 81.6 & 84.7 & $<0.000$ & 30.8 & 78.6 & 78.5 & 83.0 & $<0.000$ \\
\hline \multirow{3}{*}{ Regional products } & 1 & $172 / 1,351$ & 12.7 & 11.8 & 18.0 & & 9.7 & 15.8 & & 25.7 & 8.4 & 7.9 & & 46.2 & 12.3 & 12.3 & 12.7 & \\
\hline & 2 & $257 / 1,351$ & 19.0 & 18.9 & 19.4 & & 17.1 & 21.1 & & 21.4 & 18.8 & 17.0 & & 23.1 & 19.2 & 17.3 & 21.2 & \\
\hline & 3 & $922 / 1,351$ & 68.2 & 69.3 & 62.7 & 0.058 & 73.2 & 63.1 & $<0.000$ & 52.9 & 72.9 & 75.1 & $<0.000$ & 30.8 & 68.5 & 70.4 & 66.1 & 0.016 \\
\hline \multirow{3}{*}{$\begin{array}{l}\text { Simple and fast food } \\
\text { (e.g. fast food, frozen products, } \\
\text { currywurst) }\end{array}$} & 1 & $925 / 1,352$ & 68.4 & 69.3 & 63.9 & & 75.7 & 60.8 & & 61.7 & 68.1 & 76.3 & & 7.7 & 64.9 & 73.1 & 77.4 & \\
\hline & 2 & 238/1,352 & 17.6 & 17.8 & 16.7 & & 13.4 & 22.0 & & 16.8 & 19.4 & 14.6 & & 38.5 & 17.8 & 15.1 & 22.6 & \\
\hline & 3 & $189 / 1,352$ & 14.0 & 12.9 & 19.4 & 0.014 & 10.9 & 17.2 & $<0.000$ & 21.4 & 12.5 & 9.2 & $<0.000$ & 53.8 & 17.3 & 11.8 & 13.7 & $<0.000$ \\
\hline \multirow[t]{3}{*}{ Well tasty food } & 1 & $52 / 1,353$ & 3.8 & 3.7 & 4.6 & & 3.9 & 3.8 & & 5.8 & 2.5 & 5.0 & & 0.0 & 3.6 & 5.0 & 3.3 & \\
\hline & 2 & $137 / 1,353$ & 10.1 & 10.6 & 7.4 & & 9.1 & 11.2 & & 9.8 & 10.9 & 9.0 & & 0.0 & 11.4 & 7.5 & 11.6 & \\
\hline & 3 & $1,164 / 1,353$ & 86.0 & 85.7 & 88.0 & 0.337 & 87.0 & 85.0 & 0.313 & 84.4 & 86.6 & 86.0 & 0.651 & 100.0 & 85.0 & 87.5 & 85.0 & 0.294 \\
\hline Adequate fruit and vegetable & 1 & 147/1,352 & 10.9 & 9.8 & 16.7 & & 6.4 & 15.6 & & 13.9 & 11.8 & 6.3 & & 38.5 & 11.9 & 11.3 & 9.8 & \\
\hline intake (5 a day) & 2 & $263 / 1,352$ & 19.5 & 18.8 & 23.1 & & 15.5 & 23.6 & & 22.9 & 20.5 & 13.4 & & 38.5 & 21.1 & 20.5 & 17.5 & \\
\hline & 3 & $943 / 1,352$ & 69.7 & 71.5 & 60.2 & 0.001 & 78.1 & 60.8 & $<0.000$ & 63.5 & 67.9 & 80.6 & $<0.000$ & 23.1 & 66.9 & 68.2 & 72.7 & 0.001 \\
\hline Big portions & 1 & $689 / 1,352$ & 51.0 & 51.0 & 50.5 & & 59.5 & 42.1 & & 39.6 & 52.2 & 60.7 & & 38.5 & 52.4 & 47.6 & 53.6 & \\
\hline & 2 & $414 / 1,352$ & 30.6 & 31.0 & 27.8 & & 27.1 & 34.3 & & 35.3 & 30.8 & 25.5 & & 23.1 & 25.6 & 36.5 & 29.3 & \\
\hline & 3 & $249 / 1,352$ & 18.4 & 17.9 & 20.8 & 0.325 & 13.5 & 23.6 & $<0.000$ & 25.1 & 17.1 & 20.2 & $<0.000$ & 38.5 & 22.0 & 15.9 & 17.0 & 0.017 \\
\hline Vegetarian/vegan food & 1 & $883 / 1,348$ & 65.5 & 63.6 & 75.1 & & 60.3 & 70.8 & & 63.8 & 65.4 & 67.9 & & 81.8 & 70.3 & 67.8 & 59.3 & \\
\hline & 2 & $234 / 1,348$ & 17.4 & 18.1 & 13.8 & & 19.7 & 15.0 & & 14.2 & 17.9 & 19.7 & & 0.0 & 18.3 & 15.6 & 18.7 & \\
\hline & 3 & $231 / 1,348$ & 17.1 & 18.3 & 11.1 & 0.007 & 20.0 & 14.2 & 0.005 & 22.3 & 29.6 & 12.4 & 0.004 & 18.2 & 11.4 & 16.5 & 22.0 & $<0.000$ \\
\hline On my mental state based food & 1 & $258 / 1,334$ & 19.3 & 10.2 & 19.2 & & 12.9 & 26.0 & & 30.0 & 13.7 & 19.8 & & 46.2 & 14.5 & 21.3 & 20.4 & \\
\hline & 2 & $320 / 1,334$ & 24.0 & 23.1 & 28.5 & & 23.8 & 24.0 & & 25.4 & 25.0 & 20.1 & & 15.4 & 24.5 & 26.1 & 21.4 & \\
\hline & 3 & $756 / 1,334$ & 56.7 & 57.5 & 52.3 & 0.148 & 63.3 & 50.0 & $<0.000$ & 44.6 & 61.3 & 60.1 & $<0.000$ & 38.5 & 61.0 & 52.6 & 58.2 & 0.059 \\
\hline Food high in protein & 1 & $289 / 1,338$ & 21.6 & 21.5 & 21.5 & & 20.2 & 22.9 & & 22.7 & 23.8 & 15.7 & & 23.1 & 18.8 & 21.4 & 23.9 & \\
\hline & 2 & $568 / 1,338$ & 42.5 & 43.1 & 39.3 & & 40.7 & 44.2 & & 37.2 & 44.9 & 42.9 & & 15.4 & 46.6 & 43.0 & 39.6 & \\
\hline & 3 & $481 / 1,338$ & 36.0 & 35.4 & 39.4 & 0.290 & 39.0 & 32.9 & 0.021 & 40.1 & 31.2 & 41.3 & 0.002 & 53.8 & 34.6 & 35.6 & 36.5 & 0.403 \\
\hline
\end{tabular}




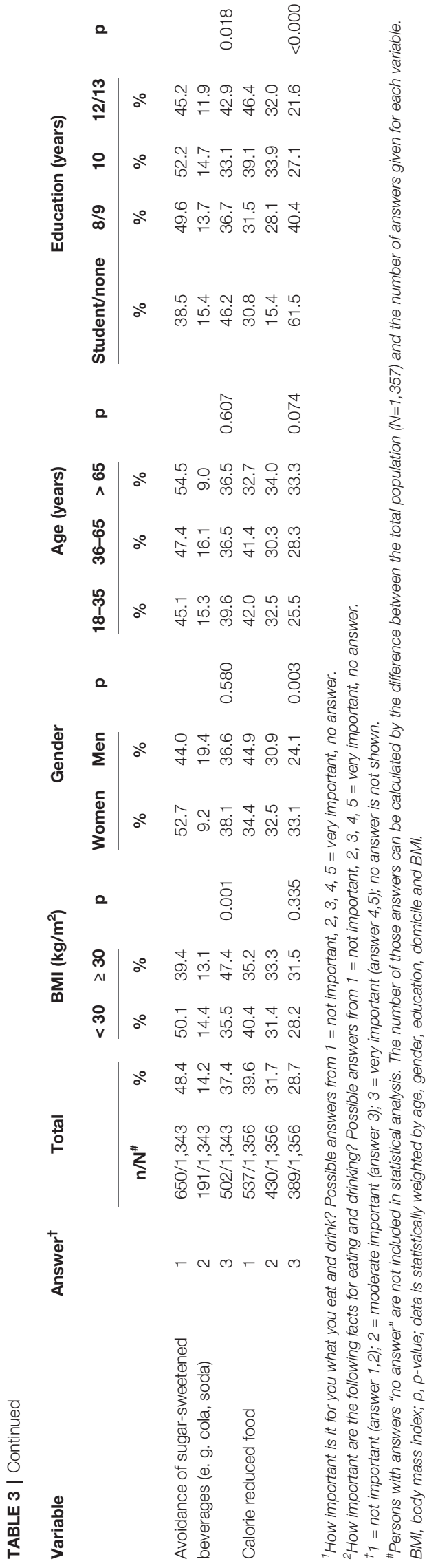

$(\mathrm{p} \leq 0.05)$. Women showed a higher willingness to support political approaches for a healthy diet than men, depending on the kind of political regulatory action $(\mathrm{p} \leq 0.05)$. The percental distribution of most of the political approaches was significantly different between the age groups $(p \leq 0.01)$. Similar results could be found when comparing the different education groups $(\mathrm{p} \leq 0.01)$.

\section{DISCUSSION}

This survey provided representative data on the general population's opinion in Germany about who is responsible for the development of obesity and for promoting a healthy diet. Over $80 \%$ of the survey population stated that excessive caloric intake and low physical activity are causes of a high body weight. Furthermore, over $70 \%$ of participants indicated that a lack of will power is another cause for a high body weight. In their recent survey, Kim et al. (21) compared the obesity stigma between Germany and the US. In the German survey, a person with obesity was assigned the following attributes: poor self-control, no will power, self-indulgent, inactive, shapeless, slow, unattractive, lacking endurance, overeating, and liking food (21). In summary, becoming obese was seen as a general loss of self-control. Likewise, almost $90 \%$ of this survey population thought that the responsibility for adhering to a healthy diet lies with the individual. Moreover, persons with BMI $\geq 30 \mathrm{~kg} / \mathrm{m}^{2}$ named the individual's responsibility towards a healthy diet more often than those with $\mathrm{BMI}<30 \mathrm{~kg} / \mathrm{m}^{2}$.

Obesity is recognized as a complex chronic disease in the scientific community (15). The judgment of self-blaming, described above, which is often ascribed to individuals with obesity may represent a general misunderstanding and underestimation of the genetic influence on the regulation of body weight and the impact of external drivers. Indeed, a broad misunderstanding may explain, at least in part, the high prevalence of weight-related stigma in the population and society in general. People with obesity are confronted with weight-related stigma through the media $(22,23)$, the health care system $(24,25)$, the workplace $(25)$, educational settings, and friends and family $(25,26)$. Several studies pointed out that weight-related stigma can lead to negative outcomes, e.g. increased physiological dysfunction (27), as well as decreased cardiovascular $(28)$ and mental health $(12,14)$. Moreover, weight-related stigma is associated with increased weight and waist circumference $(13,29)$ and increased risk of becoming overweight (29). This might be due to a higher consumption of food, a confirmed association between weight-related stigma and binge eating (30), and decreased motivation for physical activity (31). The latter may be explained by the fact that people with obesity tend to avoid places in which weight-related stigma occurs (31). Thereby, a vicious cycle may occur, resulting from a combination of stigmatization from oneself as well as from others. It is essential that the society as a whole, including affected persons, experts, media, stakeholders and the general public, recognizes that obesity is a chronic disease that is impacted by e.g. genetic, physiological, psychosocial and 


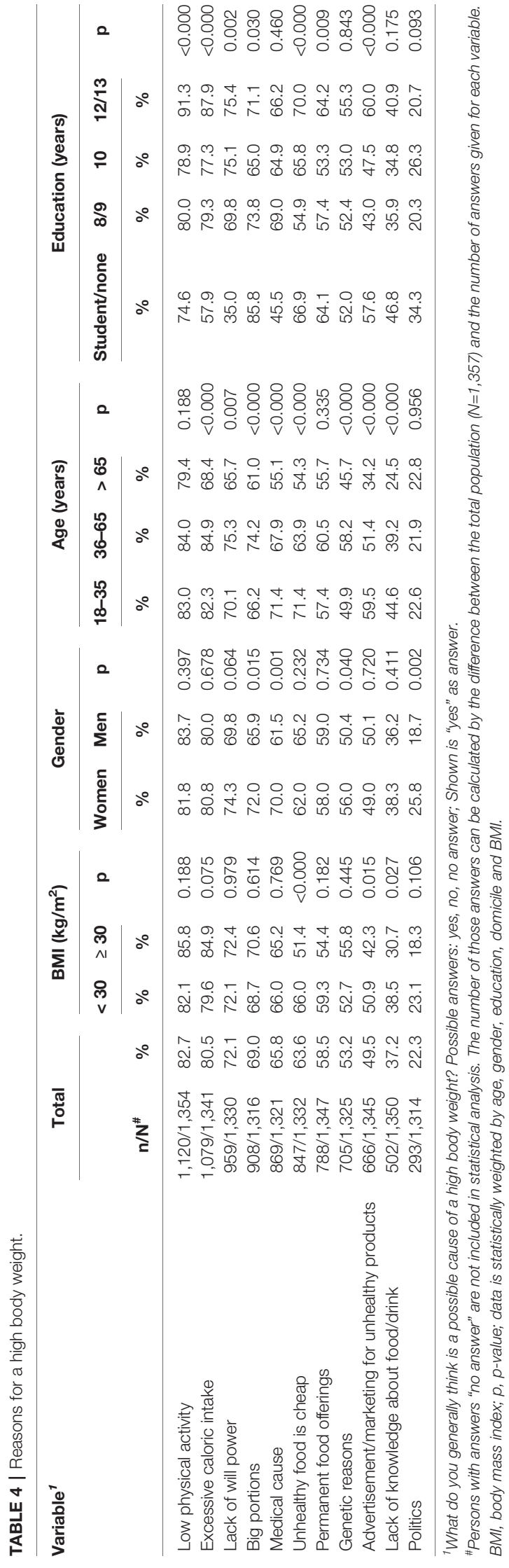

environmental factors. Ultimately, this shift in perspective may contribute to improved preventive and therapeutic strategies.

Approaches for the prevention and treatment of obesity on an individual level have shown little effect (32). As the development of obesity is influenced through micro- as well as through macrosettings (32), several strategies focusing on these settings were established $(32,33)$. The WHO indicated that food choices are influences by several determinants, e.g. price and availability. Moreover, advertisement of unhealthy food promotes poor food choices among children and adolescents (32). In their strategy paper for primary prevention, the German Alliance against NCDs stated four approaches which focused on the macro level: increasing physical activity among children and adolescents (primarily in school), food taxation, healthier food in kindergarten and school, and banning advertisement for unhealthy food and beverages (33). A systematic review focusing on the effects of environmental interventions on the consumption of sugar-sweetened beverages found evidence that several strategies are associated with a reduced consumption of sugar-sweetened beverages. In particular, they observed that food labeling and increased prices led to reduced consumption of sugar-sweetened beverages (34). Over $70 \%$ of the survey population presented herein indicated that they would support the following political actions: traffic light labelling, lowering of prices for healthy food, improving food quality, awareness campaigns, promoting regional and seasonal foods, nutrition education in school and promoting a healthy diet in kindergarten. Surprisingly, increasing prices and banning the advertisement of unhealthy food was named as appropriate strategies by $50 \%$ of this survey population. This suggests that half of the respondents, independent of the BMI, are generally accepting political interventions to reduce an obesogenic environment. A recently published German survey with 1,035 persons found similar results (35). About $64 \%$ of the participants were in favor for political strategies concerning healthier food. Furthermore, Jürkenbeck et al. (35) has shown that the support of political strategies was independent of the struggle of choosing healthy food.

Our data showed that the most frequently used strategies for weight reduction were increased physical activity, a caloriereduced diet, a low-carb diet, and a low-fat diet. Adherence to a weight loss program, either at a medical center or a commercially available program such as Weight Watchers ${ }^{\circledR}$, weight loss medications or surgery were reported as weight loss strategies by less than $10 \%$ of the survey population. Persons with a BMI $\geq$ $30 \mathrm{~kg} / \mathrm{m}^{2}$ named professional programs or the intake of medication more often than those with a BMI $<30 \mathrm{~kg} / \mathrm{m}^{2}$. Our results suggest that people with overweight or obesity are more likely to apply self-selected methods to losing weight rather than following evidence-based therapies. Furthermore, these results indicate that people with overweight or obesity do not get the help they needed and have to deal with their weight problems on their own. However, as the survey population was not asked whether they decided on the weight loss strategy on their own or whether the strategy was selected or performed by a nutritional specialist this is just an assumption. Continuously given advice for a healthy lifestyle in the media (22) and the common opinion 
TABLE 5 | Responsibility for a person's healthy diet.

\begin{tabular}{|c|c|c|c|c|c|c|c|c|c|c|c|c|c|c|c|c|c|c|c|}
\hline \multirow[t]{3}{*}{ Variable $^{1}$} & \multirow[t]{3}{*}{ Answer ${ }^{\dagger}$} & \multicolumn{2}{|l|}{ Total } & \multicolumn{3}{|c|}{ BMI $\left(\mathrm{kg} / \mathrm{m}^{2}\right)$} & \multicolumn{3}{|c|}{ Gender } & \multicolumn{4}{|c|}{ Age (years) } & \multicolumn{5}{|c|}{ Education (years) } & \multirow[b]{3}{*}{$\%$} \\
\hline & & $\mathrm{n} / \mathrm{N}$ & $\#$ & $<30$ & $\geq \mathbf{3 0}$ & p & Women & Men & p & $18-35$ & $36-65$ & $>65$ & $\mathbf{p}$ & Student/none & $8 / 9$ & 10 & $12 / 13$ & $p$ & \\
\hline & & & & $\%$ & $\%$ & & $\%$ & $\%$ & & $\%$ & $\%$ & $\%$ & & $\%$ & $\%$ & $\%$ & $\%$ & & \\
\hline \multirow[t]{3}{*}{ Politics } & 1 & $581 / 1,337$ & 43.5 & 43.6 & 43.1 & & 41.3 & 45.7 & & 46.8 & 42.2 & 42.4 & & 46.2 & 43.2 & 46.6 & 38.2 & & \\
\hline & 2 & $295 / 1,337$ & 22.1 & 22.0 & 22.0 & & 22.0 & 22.1 & & 18.0 & 24.8 & 20.4 & & 23.1 & 23.0 & 20.1 & 24.3 & & \\
\hline & 3 & $462 / 1,337$ & 34.6 & 34.5 & 35.0 & 0.875 & 36.6 & 32.4 & 0.095 & 35.2 & 33.0 & 37.2 & 0.418 & 30.8 & 34.1 & 33.2 & 37.4 & 0.593 & \\
\hline \multirow[t]{3}{*}{ Health insurance } & 1 & $473 / 1,340$ & 35.3 & 35.6 & 33.4 & & 32.9 & 37.7 & & 38.4 & 35.5 & 31.2 & & 23.1 & 34.0 & 32.0 & 38.8 & & \\
\hline & 2 & $374 / 1,340$ & 27.9 & 28.2 & 26.3 & & 28.4 & 27.4 & & 28.5 & 29.3 & 24.0 & & 7.7 & 24.9 & 30.8 & 29.6 & & \\
\hline & 3 & $493 / 1,340$ & 36.8 & 36.1 & 40.3 & 0.221 & 38.5 & 35.0 & 0.175 & 33.1 & 35.1 & 44.9 & 0.003 & 69.3 & 40.8 & 37.0 & 31.3 & 0.001 & \\
\hline \multirow[t]{3}{*}{ Medicine } & 1 & $347 / 1,338$ & 25.9 & 26.3 & 24.4 & & 23.3 & 28.9 & & 28.8 & 27.3 & 19.9 & & 53.9 & 22.5 & 29.1 & 24.6 & & \\
\hline & 2 & $350 / 1,338$ & 26.2 & 25.0 & 33.0 & & 27.3 & 25.0 & & 25.6 & 26.6 & 26.0 & & 15.4 & 30.3 & 23.9 & 28.0 & & \\
\hline & 3 & $640 / 1,338$ & 47.8 & 48.9 & 43.0 & 0.088 & 50.3 & 46.2 & 0.255 & 45.6 & 46.0 & 54.2 & 0.038 & 30.8 & 47.2 & 47.0 & 47.3 & 0.763 & \\
\hline \multirow[t]{3}{*}{ Media } & 1 & $360 / 1,342$ & 26.8 & 26.4 & 28.7 & & 24.0 & 29.7 & & 28.2 & 24.8 & 29.5 & & 51.8 & 32.4 & 28.0 & 20.8 & & \\
\hline & 2 & $358 / 1,342$ & 26.7 & 26.4 & 28.8 & & 26.8 & 26.6 & & 22.4 & 31.1 & 21.9 & & 0.0 & 27.9 & 26.1 & 27.1 & & \\
\hline & 3 & $623 / 1,342$ & 46.4 & 47.2 & 42.5 & 0.223 & 49.2 & 43.6 & 0.038 & 49.4 & 44.1 & 48.2 & 0.216 & 48.2 & 39.9 & 46.4 & 52.0 & 0.006 & \\
\hline \multirow[t]{3}{*}{ Food industry } & 1 & $240 / 1,338$ & 17.9 & 17.9 & 18.7 & & 14.3 & 21.6 & & 17.2 & 15.2 & 24.6 & & 27.9 & 18.8 & 20.9 & 11.7 & & \\
\hline & 2 & $256 / 1,338$ & 19.1 & 19.1 & 19.2 & & 19.5 & 18.9 & & 21.3 & 19.9 & 15.2 & & 8.0 & 19.4 & 19.7 & 20.4 & & \\
\hline & 3 & $840 / 1,338$ & 62.8 & 63.0 & 61.7 & 0.796 & 66.2 & 59.4 & 0.010 & 61.5 & 64.8 & 59.7 & 0.259 & 64.1 & 61.8 & 59.3 & 68.2 & 0.043 & \\
\hline \multirow[t]{3}{*}{ Family } & 1 & $115 / 1,347$ & 8.5 & 8.2 & 10.3 & & 6.7 & 10.4 & & 5.9 & 8.4 & 11.7 & & 7.7 & 8.9 & 8.6 & 6.0 & & \\
\hline & 2 & $227 / 1,347$ & 16.9 & 16.2 & 20.2 & & 14.6 & 19.2 & & 19.1 & 15.9 & 16.1 & & 38.5 & 25.1 & 15.5 & 11.4 & & \\
\hline & 3 & $1,006 / 1,347$ & 74.7 & 75.6 & 70.0 & 0.079 & 78.8 & 70.4 & $<0.000$ & 74.9 & 75.5 & 72.2 & 0.490 & 53.8 & 66.3 & 76.0 & 82.3 & $<0.000$ & \\
\hline \multirow[t]{3}{*}{ The individual } & 1 & $32 / 1,343$ & 2.4 & 2.4 & 2.0 & & 1.9 & 2.9 & & 2.9 & 1.75 & 9.8 & & 0.0 & 2.7 & 3.1 & 1.3 & & \\
\hline & 2 & $113 / 1,343$ & 8.4 & 9.3 & 3.9 & & 5.3 & 11.6 & & 6.0 & 9.5 & 5.0 & & 0.0 & 9.4 & 7.8 & 6.1 & & \\
\hline & 3 & $1,197 / 1,343$ & 89.1 & 88.3 & 94.1 & 0.011 & 92.8 & 85.5 & $<0.000$ & 90.0 & 88.8 & 84.6 & 0.845 & 100.0 & 87.9 & 89.1 & 92.6 & 0.068 & \\
\hline \multirow[t]{3}{*}{ Cafeteria } & 1 & $247 / 1,282$ & 19.3 & 19.8 & 16.5 & & 20.4 & 17.9 & & 15.5 & 18.6 & 24.6 & & 18.1 & 23.3 & 19.8 & 13.7 & & \\
\hline & 2 & $325 / 1,282$ & 25.4 & 25.1 & 26.4 & & 22.6 & 28.3 & & 25.8 & 27.5 & 20.1 & & 0.0 & 23.4 & 26.5 & 25.8 & & \\
\hline & 3 & $711 / 1,282$ & 55.5 & 55.1 & 57.0 & 0.514 & 57.0 & 53.8 & 0.268 & 58.7 & 53.8 & 55.3 & 0.344 & 81.8 & 53.0 & 53.8 & 60.2 & 0.031 & \\
\hline \multirow[t]{3}{*}{ School } & 1 & $213 / 1,291$ & 16.4 & 16.3 & 18.1 & & 14.1 & 19.0 & & 17.1 & 14.0 & 21.0 & & 38.5 & 17.1 & 15.0 & 13.1 & & \\
\hline & 2 & $319 / 1,291$ & 24.7 & 24.9 & 23.8 & & 25.1 & 24.1 & & 22.4 & 28.2 & 19.2 & & 0.0 & 24.3 & 24.6 & 27.6 & & \\
\hline & 3 & $759 / 1,291$ & 58.9 & 58.9 & 58.5 & 0.902 & 60.6 & 57.1 & 0.175 & 60.5 & 57.7 & 59.4 & 0.682 & 69.3 & 58.6 & 60.6 & 59.1 & 0.914 & \\
\hline
\end{tabular}

${ }^{1}$ In your opinion, who is responsible for a person's healthy diet? Possible answers from $1=$ no responsibility, 2, 3, 4, 5 = high responsibility, do not know, no answer.

$11=$ no responsibility (answer 1,2); 2 = moderate responsibility (answer 3); 3 = high responsibility (answer 4,5); do not know and no answer are not shown.

"Persons with answers "no answer" or "do not know" are not included in statistical analysis. The number of those answers can be calculated by the difference between the total population ( $N=1,357)$ and the number of answers given for each variable.

BMI, body mass index; p, p-value; data is statistically weighted by age, gender, education, domicile and BMI. 
TABLE 6 | Opinions of participants about regulatory and other measures to achieve a healthy diet in the population

\begin{tabular}{|c|c|c|c|c|c|c|c|c|c|c|c|c|c|c|c|c|c|c|}
\hline \multirow[t]{3}{*}{ Variable $^{1}$} & \multirow[t]{3}{*}{ Answer ${ }^{\dagger}$} & \multicolumn{2}{|l|}{ Total } & \multicolumn{3}{|c|}{ BMI $\left(\mathrm{kg} / \mathrm{m}^{2}\right)$} & \multicolumn{3}{|c|}{ Gender } & \multicolumn{4}{|c|}{ Age (years) } & \multicolumn{5}{|c|}{ Education (years) } \\
\hline & & \multirow[t]{2}{*}{$n / N^{\#}$} & \multirow[t]{2}{*}{$\%$} & \multirow{2}{*}{$\frac{<30}{\%}$} & \multirow{2}{*}{$\frac{\geq 30}{\%}$} & \multirow[t]{2}{*}{ p } & Women & \multirow{2}{*}{$\frac{\text { Men }}{\%}$} & \multirow[t]{2}{*}{$\mathbf{p}$} & \multirow{2}{*}{$\frac{18-35}{\%}$} & \multirow{2}{*}{$\begin{array}{c}36-65 \\
\%\end{array}$} & \multirow{2}{*}{$\frac{>65}{\%}$} & \multirow[t]{2}{*}{$\mathrm{p}$} & \multirow{2}{*}{$\frac{\text { Student/none }}{\%}$} & \multirow{2}{*}{$\begin{array}{c}8 / 9 \\
\%\end{array}$} & \multirow{2}{*}{$\begin{array}{l}10 \\
\%\end{array}$} & \multirow{2}{*}{$\frac{12 / 13}{\%}$} & p \\
\hline & & & & & & & $\%$ & & & & & & & & & & & \\
\hline Taxation of specific foods & 1 & $498 / 1,323$ & 37.6 & 36.8 & 42.5 & & 38.3 & 36.9 & & 43.8 & 36.9 & 32.5 & & 69.2 & 41.4 & 42.7 & 30.1 & \\
\hline (e.g. sugar tax) & 2 & 275/1,323 & 20.8 & 22.2 & 13.7 & & 20.8 & 20.8 & & 23.8 & 21.4 & 16.1 & & 0.0 & 19.8 & 16.5 & 24.4 & \\
\hline & 3 & $550 / 1,323$ & 41.6 & 41.0 & 44.8 & 0.355 & 40.8 & 42.4 & 0.573 & 32.4 & 41.8 & 50.8 & $<0.000$ & 30.8 & 38.8 & 40.8 & 45.4 & 0.169 \\
\hline Traffic light labelling & 1 & 225/1,320 & 17.0 & 17.3 & 15.5 & & 16.7 & 17.4 & & 22.1 & 15.6 & 14.6 & & 46.2 & 12.2 & 18.7 & 16.9 & \\
\hline (e.g. red for unhealthy food) & 2 & $203 / 1,320$ & 15.4 & 16.0 & 12.2 & & 14.4 & 16.4 & & 19.5 & 16.8 & 7.8 & & 7.7 & 17.6 & 12.7 & 14.4 & \\
\hline & 3 & $892 / 1,320$ & 67.6 & 66.6 & 71.8 & 0.121 & 68.9 & 66.4 & 0.301 & 58.4 & 67.7 & 77.3 & $<0.000$ & 46.2 & 70.5 & 68.7 & 68.4 & 0.301 \\
\hline Lowering of prices for healthy foods & 1 & 195/1,317 & 14.8 & 15.0 & 13.7 & & 13.7 & 16.0 & & 11.8 & 16.8 & 13.6 & & 27.8 & 17.1 & 10.2 & 17.4 & \\
\hline & 2 & $204 / 1,317$ & 15.5 & 15.4 & 16.0 & & 16.1 & 15.0 & & 19.1 & 15.6 & 11.2 & & 0.0 & 9.2 & 14.6 & 22.1 & \\
\hline & 3 & $918 / 1,317$ & 69.7 & 69.5 & 70.3 & 0.895 & 570.3 & 69.1 & 0.680 & 72.1 & 67.6 & 74.7 & 0.074 & 72.2 & 73.4 & 75.2 & 60.3 & $<0.000$ \\
\hline Increasing of prices for unhealthy foods & 1 & $373 / 1,322$ & 28.2 & 28.5 & 26.9 & & 27.5 & 29.0 & & 30.9 & 27.9 & 26.1 & & 46.2 & 26.1 & 32.9 & 25.1 & \\
\hline & 2 & 295/1,322 & 22.3 & 22.3 & 22.6 & & 21.4 & 23.2 & & 26.4 & 23.1 & 16.3 & & 7.7 & 24.4 & 17.4 & 25.3 & \\
\hline & 3 & 653/1,322 & 49.4 & 49.3 & 50.0 & 0.800 & 51.0 & 47.8 & 0.236 & 42.7 & 49.0 & 57.5 & 0.001 & 46.2 & 49.3 & 49.6 & 49.5 & 1.000 \\
\hline Ban of advertising for unhealthy foods & 1 & $353 / 1,305$ & 27.0 & 26.6 & 30.1 & & 24.5 & 29.7 & & 33.7 & 25.9 & 22.3 & & 53.8 & 26.4 & 31.6 & 22.3 & \\
\hline & 2 & $271 / 1,305$ & 20.8 & 21.1 & 19.1 & & 20.4 & 21.2 & & 30.4 & 20.4 & 10.6 & & 15.4 & 11.8 & 19.8 & 28.9 & \\
\hline & 3 & $681 / 1,305$ & 52.2 & 52.5 & 51.2 & 0.687 & 55.3 & 49.1 & 0.026 & 35.9 & 53.5 & 67.1 & $<0.000$ & 30.8 & 61.8 & 48.3 & 48.1 & $<0.000$ \\
\hline Improving food quality & 1 & $128 / 1,330$ & 9.6 & 9.9 & 8.5 & & 8.8 & 10.7 & & 12.4 & 8.8 & 8.4 & & 53.8 & 7.8 & 11.6 & 7.6 & \\
\hline (e.g. less sugar) & 2 & $160 / 1,330$ & 12.0 & 12.6 & 9.0 & & 9.1 & 15.1 & & 14.7 & 12.0 & 9.0 & & 7.7 & 8.9 & 11.6 & 13.6 & \\
\hline & 3 & $1,042 / 1,330$ & 78.3 & 77.5 & 83.0 & 0.098 & 82.2 & 74.4 & 0.001 & 72.9 & 79.0 & 82.3 & 0.009 & 38.5 & 83.2 & 76.8 & 78.8 & $<0.000$ \\
\hline Awareness campaign & 1 & $117 / 1,333$ & 8.8 & 8.8 & 8.5 & & 7.4 & 10.3 & & 14.5 & 7.4 & 5.4 & & 46.2 & 7.6 & 12.4 & 6.3 & \\
\hline & 2 & $202 / 1,333$ & 15.2 & 14.3 & 19.8 & & 13.4 & 16.9 & & 19.8 & 13.7 & 13.1 & & 15.4 & 16.3 & 12.8 & 15.8 & \\
\hline & 3 & $1,014 / 1,333$ & 76.1 & 76.8 & 71.7 & 0.099 & 79.3 & 72.8 & 0.005 & 65.8 & 78.7 & 80.8 & $<0.000$ & 38.5 & 76.1 & 74.8 & 77.8 & 0.009 \\
\hline Promoting regional and seasonal foods & 1 & $84 / 1,327$ & 6.3 & 5.8 & 9.0 & & 4.6 & 8.1 & & 7.4 & 6.4 & 5.2 & & 46.2 & 7.0 & 5.5 & 5.7 & \\
\hline & 2 & $143 / 1,327$ & 10.8 & 10.3 & 13.7 & & 8.1 & 13.5 & & 13.1 & 10.5 & 9.0 & & 7.7 & 12.6 & 5.8 & 10.0 & \\
\hline & 3 & $1,099 / 1,327$ & 82.8 & 83.8 & 77.8 & 0.030 & 87.1 & 78.4 & $<0.000$ & 79.5 & 83.0 & 85.7 & 0.112 & 46.2 & 80.4 & 86.6 & 84.0 & $<0.000$ \\
\hline Nutrition education in school & 1 & $56 / 1,333$ & 4.2 & 4.5 & 2.4 & & 4.2 & 4.2 & & 5.3 & 3.9 & 3.6 & & 15.4 & 4.2 & 3.3 & 4.9 & \\
\hline & 2 & $129 / 1,333$ & 9.7 & 9.8 & 8.5 & & 7.7 & 11.7 & & 16.8 & 8.0 & 5.5 & & 30.8 & 10.7 & 8.7 & 8.9 & \\
\hline & 3 & $1,148 / 1,333$ & 86.1 & 85.5 & 89.2 & 0.199 & 88.1 & 83.9 & 0.027 & 77.9 & 88.0 & 90.0 & $<0.000$ & 53.8 & 85.1 & 88.0 & 86.1 & 0.003 \\
\hline Promoting a healthy diet in kindergarten & 1 & $73 / 1,340$ & 5.4 & 5.5 & 4.7 & & 4.7 & 6.2 & & 8.7 & 4.7 & 3.5 & & 46.2 & 6.1 & 3.5 & 4.8 & \\
\hline & 2 & $83 / 1,340$ & 6.2 & 6.6 & 4.3 & & 6.3 & 6.1 & & 11.6 & 4.2 & 4.5 & & 7.7 & 6.4 & 4.0 & 6.3 & \\
\hline & 3 & $1,185 / 1,340$ & 88.4 & 88.0 & 91.0 & 0.242 & 88.8 & 87.9 & 0.521 & 79.7 & 91.1 & 92.0 & $<0.000$ & 46.2 & 87.2 & 92.2 & 88.9 & $<0.000$ \\
\hline
\end{tabular}

${ }^{1}$ When the policy should take care of a person's healthy diet which of the following approaches would you personally prefer? Possible answers from $1=1$ disclaim, 2, $3=$ I support, do not know, no answer.

${ }_{1} 1$ = no support (answer 1); 2 = moderate support (answer 2); 3 = high support (answer 3); do not know and no answer are not shown.

"Persons with answers "no answer" or "do not know" are not included in statistical analysis. The number of those answers can be calculated by the difference between the total population ( $N=1,357)$ and the number of answers given for each variable.

BMI, body mass index; p, p-value; data is statistically weighted by age, gender, education, domicile and BMI. 
indicating that individuals are in charge of their healthy lifestyle (21) may explain why professional support is only rarely used. This is in line with the results of a survey with 14,502 people with obesity and 2,785 healthcare professionals (36). Caterson et al. (36) found out, that $81 \%$ of the participants with obesity stated that losing weight is their own responsibility. Only $26 \%$ of those named their healthcare professional as responsible for a successful weight loss (36). This is supported by the fact that the treatment of obesity is not covered by health care systems and costs have to be paid by the patients themselves. Therefore, it is crucial to raise awareness of obesity as a chronic disease both in the general population and among stakeholders.

When asked about personal eating and drinking behaviors, almost $80 \%$ of the survey population stated that eating and drinking is important for them. Due to the question asked it is not possible to specify this result. Self-prepared and fresh meals, adequate fluids, healthy and tasty foods are important factors for the selection of eating and drinking offerings. However, the comparison of persons with and without obesity showed different results. For people with $\mathrm{BMI} \geq 30 \mathrm{~kg} / \mathrm{m}^{2}$, eating and drinking seemed to be less important than for those without obesity. Furthermore, factors like fiber intake, balanced and healthy food, fruit and vegetable intake and vegetarian/vegan food were less stated to be important for those with BMI $\geq 30 \mathrm{~kg} / \mathrm{m}^{2}$ than for those with BMI $<30 \mathrm{~kg} / \mathrm{m}^{2}$. This is in line with the other results observed. Persons with BMI $\geq 30 \mathrm{~kg} / \mathrm{m}^{2}$ blame themselves for being personally responsible for their high body weight by choosing a less healthy diet. Moreover, having a lack of knowledge about food and drink was stated significantly less by persons with $\mathrm{BMI} \geq$ $30 \mathrm{~kg} / \mathrm{m}^{2}$ than those with $\mathrm{BMI}<30 \mathrm{~kg} / \mathrm{m}^{2}$. This might indicate, that even though most persons with obesity have knowledge about a healthy diet, the negative effects of self-blaming and weightrelated stigma hold up the vicious circle and prevent persons with obesity from living a healthy lifestyle. Therefore, reducing weightrelated stigma and increasing the knowledge of obesity to be a chronic disease is crucial for the prevention and treatment of obesity.

This survey provides data on the opinion of a representative and rather large sample regarding the responsibility of stakeholders for obesity and a healthy diet in Germany. The study-specific questionnaire was developed by experts and the interviews were conducted in a standardized manner (CATI method) by a professional agency. However, several limitations should be mentioned.

The anthropometric data for the BMI calculation was obtained by self-report. However, this has been accepted as a valid method $(37,38)$. Although the systematic short screening of additional individuals to have more participants with $\mathrm{BMI} \geq 30.0$ $\mathrm{kg} / \mathrm{m}^{2}$ might have methodological limitations, the standardized use of an RDD sampling method and the statistical weighting of data (according to age, gender, education, domicile, and BMI) produced representative data for adults in Germany. However, this data is also biased by participation of people who are motivated for surveys and interested in the given topic. In addition, it has to be mentioned that this survey is focused on diet as one of the main factors associated with overweight and obesity. It might be of added value to extend the results by parameters of physical activity. Besides, data on personal health determinants such as self-efficacy would enrich the findings. As most of the questions asked were close-ended, the results are limited to given answers and might be biased to give a certain self-selected response. However, the survey is strengthened by the fact, that the different answer options within one question were randomly chosen for each participant to avoid order bias.

Based on the results of this survey and the findings of the policymaker survey from EASO (16) the following implications may be derived. First, an increased awareness that obesity is a chronic disease and not self-inflicted is necessary for a more successful strategy to prevent and to treat obesity. Educating the public that obesity is a multifactorial disease is key to reducing stigmatization and discrimination. Second, policymakers should understand their role in setting and implementing a public health agenda that promotes a healthy lifestyle, reduces an obesogenic environment, and provides better access to services for those who struggle with obesity. Finally, healthcare professionals should be given the tools and education to allow them to adequately manage and support their patients with obesity, including addressing the complex nature of obesity as a medical condition. The findings from this survey support the need for a multidisciplinary approach from all members of society to tackle the obesity epidemic (39) and to reframe obesity as a chronic disease that requires individual, societal and political engagement to plan better prevention and treatment strategies.

\section{CONCLUSIONS}

In this survey, the opinions of the general population on the responsibilities of individuals and stakeholders for obesity and a healthy diet were assessed. Most of the survey participants indicated that obesity is caused by self-controlled attitudes and individuals are personally responsible for a healthy diet. These beliefs may promote the development of a weight-related stigma in the population. Hence, more education and communication concerning the true and complex causes of obesity are needed to reduce weight-related stigma. Furthermore, the survey population revealed a high acceptance of political approaches to facilitate a healthy diet. Therefore, the time has come to address the obesogenic environment to promote and achieve a healthier lifestyle in the general population.

\section{DATA AVAILABILITY STATEMENT}

The datasets generated for this study are available on request to the corresponding author.

\section{ETHICS STATEMENT}

Ethics committee approval: Ethical review and approval was not required for the study on human participants in accordance with the local legislation and institutional requirements. 
Consent procedures: Written informed consent from the participants was not required to participate in this study in accordance with the national legislation and the institutional requirements. Participants provided their oral informed consent prior to participation, under the premise that participation in this survey was voluntary and analyses are conducted anonymously. Oral consent is common in representative survey research in Germany in order to avoid bias through non-response.

\section{AUTHOR CONTRIBUTIONS}

SB analyzed the data and wrote the manuscript. TD designed the survey. GS analyzed the data. HH commented on the manuscript. $\mathrm{CH}$ designed the survey, analyzed data and wrote the manuscript. All authors contributed to the article and approved the submitted version.

\section{REFERENCES}

1. Finucane MM, Stevens GA, Cowan MJ, Danaei G, Lin JK, Paciorek CJ, et al. National, regional, and global trends in body-mass index since 1980: systematic analysis of health examination surveys and epidemiological studies with 960 country-years and 9.1 million participants. Lancet (2011) 377(9765):557-67. doi: 10.1016/S0140-6736(10)62037-5

2. Ng M, Fleming T, Robinson M, Thomson B, Graetz N, Margono C, et al. Global, regional, and national prevalence of overweight and obesity in children and adults during 1980-2013: a systematic analysis for the Global Burden of Disease Study 2013. Lancet (2014) 384(9945):766-81. doi: 10.1016/ S0140-6736(14)60460-8

3. Seidell JC, Halberstadt J. The global burden of obesity and the challenges of prevention. Ann Nutr Metab (2015) 66 Suppl 2:7-12. doi: 10.1159/000375143

4. Mensink GBM, Schienkiewitz A, Haftenberger M, Lampert T, Ziese T, Scheidt-Nave C. Übergewicht und Adipositas in Deutschland. Ergebnisse der Studie zur Gesundheit Erwachsener in Deutschland (DEGS1). Bundesgesundheitsbl (2013) 56:786-94. doi: 10.1007/s00103-012-1256-3

5. World Health Organization. Obestiy and overweight. https://www.who.int/ news-room/fact-sheets/detail/obesity-and-overweight World Health Organization. (2012) [Accessed December 6 2019].

6. Webber L, Divajeva D, Marsh T, McPherson K, Brown M, Galea G, et al. The future burden of obesity-related diseases in the 53 WHO European-Region countries and the impact of effective interventions: a modelling study. BMJ Open (2014) 4(7):e004787. doi: 10.1136/bmjopen-2014-004787

7. World Health Organization. Noncommunicable diseases country profiles 2018. World Health Organization (2018). p. 223.

8. Brug J, Oenema A, Ferreira I. Theory, evidence and Intervention Mapping to improve behavior nutrition and physical activity interventions. Int J Behav Nutr Phys Act (2005) 2(1):2. doi: 10.1186/1479-5868-2-2

9. Collaboration, N.C.D.R.F. Worldwide trends in body-mass index, underweight, overweight, and obesity from 1975 to 2016: a pooled analysis of 2416 population-based measurement studies in 128.9 million children, adolescents, and adults. Lancet (London England) (2017) 390(10113):262742. doi: 10.1016/S0140-6736(17)32129-3

10. Townshend T, Lake A. Obesogenic environments: current evidence of the built and food environments. Perspect Public Health (2017) 137(1):38-44. doi: $10.1177 / 1757913916679860$

11. World Health Organization. (2016). Action Plan for the Prevention and Control of Noncommunicable Diseases in the WHO European Region. Copenhagen: WHO Regional Office for Europe. http://www.euro.who.int/: data/assets/pdf_file/0008/346328/NCD-ActionPlan-GB.pdf?ua=1 [Accessed December 6 2019].

\section{FUNDING}

This article was supported by a grant of the German Federal Ministry of Education and Research (Bundesministerium für Bildung und Forschung, BMBF, funding code: 01EA1709, enable publication number: 051). This article was written by the Junior Research Group "Personalized Nutrition \& eHealth" within the Nutrition Cluster enable. This work was also supported by the German Research Foundation (DFG) and the Technical University of Munich (TUM) in the framework of the Open Access Publishing Program.

\section{ACKNOWLEDGMENTS}

The authors thank all persons participating in the survey as well as USUMA GmbH for data collection and support for data analysis. Furthermore, we thank Dorothy Meyer for English editing and proofreading the manuscript.

12. Pearl RL, White MA, Grilo CM. Weight bias internalization, depression, and self-reported health among overweight binge eating disorder patients. Obesity (Silver Spring) (2014) 22(5):E142-148. doi: 10.1002/oby.20617

13. Puhl RM, Wall MM, Chen C, Bryn Austin S, Eisenberg ME, NeumarkSztainer D. Experiences of weight teasing in adolescence and weight-related outcomes in adulthood: A 15-year longitudinal study. Prev Med (2017) 100:173-9. doi: 10.1016/j.ypmed.2017.04.023

14. Emmer C, Bosnjak M, Mata J. The association between weight stigma and mental health: A meta-analysis. Obes Rev (2019) 21:e12953. doi: 10.1111/obr.12935

15. Bray GA, Kim KK, Wilding JPH. World Obesity Federation. Obesity: a chronic relapsing progressive disease process. A position statement of the World Obesity Federation. Obes Rev (2017) 18(7):715-23. doi: 10.1111/ obr. 12551

16. Cooper K. Obesity: perception and policy - multi-country review and survey of policymakers. London: European Association for the Study of Obesity. (2014) https://www.seedo.es/images/site/C3_EASO_Survey_A4_Web-FINAL.pdf [Accessed December 6 2019].

17. Kloosterboer SM, van den Brekel K, Rengers AH, Peek N, de Wit NJ. An exploration of beliefs and attitudes regarding healthy lifestyle behaviour in an urban population in The Netherlands: Results from a focus group study in a community-based prevention project. Eur J Public Health (2015) 25(3):46771. doi: 10.1093/eurpub/cku140

18. WHO Consultation on Obesity, World Health Organization. Obesity: prevention and managing the global epidemic: report of a WHO consultation. World Health Organization (2000). p. 252.

19. Simpson L, Tranmer M. Combining Sample and Census Data in Small Area Estimates: Iterative Proportional Fitting with Standard Software. Prof Geographer (2005) 57(2):222-34. doi: 10.1111/j.0033-0124.2005.00474.x

20. R Core Team. R: A language and environment for statistical computing. Vienna, Austria: R Foundation for Statistical Computing (2019). Available: https://www.R-project.org/.

21. Kim TJ, Makowski AC, von dem Knesebeck O. Obesity stigma in Germany and the United States - Results of population surveys. PloS One (2019) 14(8): e0221214. doi: 10.1371/journal.pone.0221214

22. Kim SH, Willis LA. Talking about obesity: news framing of who is responsible for causing and fixing the problem. J Health Commun (2007) 12(4):359-76. doi: 10.1080/10810730701326051

23. Ata RN, Thompson JK. Weight bias in the media: a review of recent research. Obes Facts (2010) 3(1):41-6. doi: 10.1159/000276547

24. Eisenberg D, Noria S, Grover B, Goodpaster K, Rogers AM. American Society for Metabolic and Bariatric Surgery Clinical Issues Committee. ASMBS position statement on weight bias and stigma. Surg Obes Relat Dis (2019) 15(6):814-21. doi: 10.1016/j.soard.2019.04.031 
25. Pearl RL, Himmelstein MS, Puhl RM, Wadden TA, Wojtanowski AC, Foster GD. Weight bias internalization in a commercial weight management sample: prevalence and correlates. Obes Sci Pract (2019) 5(4):342-53. doi: 10.1002/ osp4.354

26. Salas XR, Forhan M, Caulfield T, Sharma AM, Raine KD. Addressing Internalized Weight Bias and Changing Damaged Social Identities for People Living With Obesity. Front Psychol (2019) 10:1409. doi: 10.3389/ fpsyg.2019.01409

27. Daly M, Sutin AR, Robinson E. Perceived Weight Discrimination Mediates the Prospective Association Between Obesity and Physiological Dysregulation: Evidence From a Population-Based Cohort. Psychol Sci (2019) 30(7):1030-9. doi: 10.1177/0956797619849440

28. Panza GA, Puhl RM, Taylor BA, Zaleski AL, Livingston J, Pescatello LS. Links between discrimination and cardiovascular health among socially stigmatized groups: A systematic review. PloS One (2019) 14(6):e0217623. doi: 10.1371/ journal.pone.0217623

29. Sutin AR, Terracciano A. Perceived weight discrimination and obesity. PloS One (2013) 8(7):e70048. doi: 10.1371/journal.pone.0070048

30. Himmelstein MS, Puhl RM, Quinn DM. Overlooked and Understudied: Health Consequences of Weight Stigma in Men. Obesity (Silver Spring) (2019) 27(10):1598-605. doi: 10.1002/oby.22599

31. Vartanian LR, Shaprow JG. Effects of weight stigma on exercise motivation and behavior: a preliminary investigation among college-aged females. J Health Psychol (2008) 13(1):131-8. doi: 10.1177/1359105307084318

32. World Health Organization. The challenge of obesitiy in the WHO European region and the strategies for response: summary. Copenhagen: WHO Regional Office for Europe (2007). 324 p.

33. Effertz T, Garlichs D, Gerlach S, James Müller M, Pötschke-Langer M, Prümel-Philippsen U, et al. Wirkungsvolle Prävantion chronischer Erkrankungen: Strategiepaper der NCD-Allianz zur Primärprävention. Präv Gesundheitsf (2015) 10(1):95-100. doi: 10.1007/s11553-014-0483-9

34. von Philipsborn P, Stratil JM, Burns J, Busert LK, Pfadenhauer LM, Polus S, et al. Environmental interventions to reduce the consumption of sugarsweetened beverages and their effects on health. Cochrane Database Syst Rev (2019) 6:1465-858. doi: 10.1002/14651858.CD012292.pub2
35. Jürkenbeck K, Zuhlsdorf A, Spiller A. Nutrition Policy and Individual Struggle to Eat Healthily: The Question of Public Support. Nutrients (2020) 12:516. doi: $10.3390 /$ nu12020516

36. Caterson ID, Alfadda AA, Auerbach P, Coutinho W, Cuevas A, Dicker D, et al. Gaps to bridge: Misalignment between perception, reality and actions in obesity. Diabetes Obes Metab (2019) 21:1914-24. doi: 10.1111/dom.13752

37. Moreira NF, Luz VG, Moreira CC, Pereira RA, Sichieri R, Ferreira MG, et al. Self-reported weight and height are valid measures to determine weight status: results from the Brazilian National Health Survey (PNS 2013). Cad Saude Publ (2018) 34(5):e00063917. doi: 10.1590/0102-311X00063917

38. Neermark S, Holst C, Bisgaard T, Bay-Nielsen M, Becker U, Tolstrup JS. Validation and calibration of self-reported height and weight in the Danish Health Examination Survey. Eur J Public Health (2019) 29(2):291-6. doi: 10.1093/eurpub/cky187

39. Swinburn BA, Sacks G, Hall KD, McPherson K, Finegood DT, Moodie ML, et al. The global obesity pandemic: shaped by global drivers and local environments. Lancet (2011) 378(9793):804-14. doi: 10.1016/S0140-6736 (11)60813-1

Conflict of Interest: $\mathrm{CH}$ is a member of the scientific advisory board of 4sigma $\mathrm{GmbH}$ (Oberhaching, Germany). $\mathrm{HH}$ is a member of the scientific advisory board of the Almeda GmbH (Munich, Germany) and the Oviva AG (Zurich, Switzerland).

The remaining authors declare that the research was conducted in the absence of any commercial or financial relationships that could be construed as a potential conflict of interest.

Copyright (c) 2020 Bayer, Drabsch, Schauberger, Hauner and Holzapfel. This is an open-access article distributed under the terms of the Creative Commons Attribution License (CC BY). The use, distribution or reproduction in other forums is permitted, provided the original author(s) and the copyright owner(s) are credited and that the original publication in this journal is cited, in accordance with accepted academic practice. No use, distribution or reproduction is permitted which does not comply with these terms. 